\title{
Investigating the Knowledge Management Culture
}

\author{
Vasso Stylianou*, Andreas Savva \\ Department of Computer Science, School of Sciences and Engineering, University of Nicosia, Cyprus
}

Copyright $(2016$ by authors, all rights reserved. Authors agree that this article remains permanently open access under the terms of the Creative Commons Attribution License 4.0 International License

\begin{abstract}
Knowledge Management (KM) efforts aim at leveraging an organization into a knowledge organization thereby presenting knowledge employees with a very powerful tool; organized valuable knowledge accessible when and where needed in flexible, technologically-enhanced modes. The attainment of this aim, i.e., the transformation into a knowledge organization, depends on a number of critical success factors. One of these critical factors is the promotion of a knowledge-friendly organizational culture. This paper investigates the elements which synthesize a knowledge-friendly and simultaneously KM-enabling culture. Special interest is put on how such a culture is shaped in an educational setup.
\end{abstract}

Keywords Knowledge Management, Culture, Education

\section{Introduction}

Knowledge Management (KM) involves collecting valuable knowledge and then storing, categorizing and organizing this knowledge with the aim of making it promptly available to those people and systems that need it. Such valuable knowledge is primarily the possession of the experienced employees but may also be found in systems, databases, file cabinets, and other available sources. In order that organizations may transform into knowledge organizations it is necessary to put together coordinated efforts which will be directed towards a number of business areas. These efforts involve the alignment of the organizations' structure, the system processes, and the availability of technology and skills, with the organization's specific goal to become a knowledge organization and its broader executive goals and direction.

\subsection{Critical Success Factors for KM}

Established within the KM frameworks of implementation are a number of factors which require direct attention and are considered as critical for the success of the KM initiative. The same factors if not addressed properly and adequately may turn from being enablers into being barriers in enjoying the benefits of KM [1], [2]. KM enablers concern the organizational structure; strategy and leadership; technological infrastructure; culture; organizational processes; and measurement. If all of factors are appropriately attained to and are additionally checked to be in alignment with the goals and direction of the organization, then it is very likely that $\mathrm{KM}$ success will follow.

More analytically, key success factors for a KM implementation, a.k.a. KM enablers or KM ingredients, have been discussed in literature by several researchers such as [3], [4], (Ernst \& Young KM International Survey, 1996), [5], [6], [7], [8] among others. Hence, the long list of KM success factors which may be compiled would possibly include the following: employee training; employee involvement in KM activities; teamwork; employee motivation; employee empowerment (skills development); top management leadership and commitment in knowledge management; effective use of information and communication technologies; performance measurement to include both soft and hard measures; a knowledge-friendly organizational culture; a KM-friendly national culture (preferable); benchmarking; appropriate knowledge structure(s) (such as communities of practice); the resolution of organizational constraints; the integration and balancing of leadership, organization, learning and technology in an enterprise-wide setting; streamlined organizational structures and processes; infrastructure support as a composite of some of the above factors; a reward/recognition scheme for knowledge sharing. Several factors relate directly to the individual employee while the majority address issues at the organization level (see Figure $1)$. 


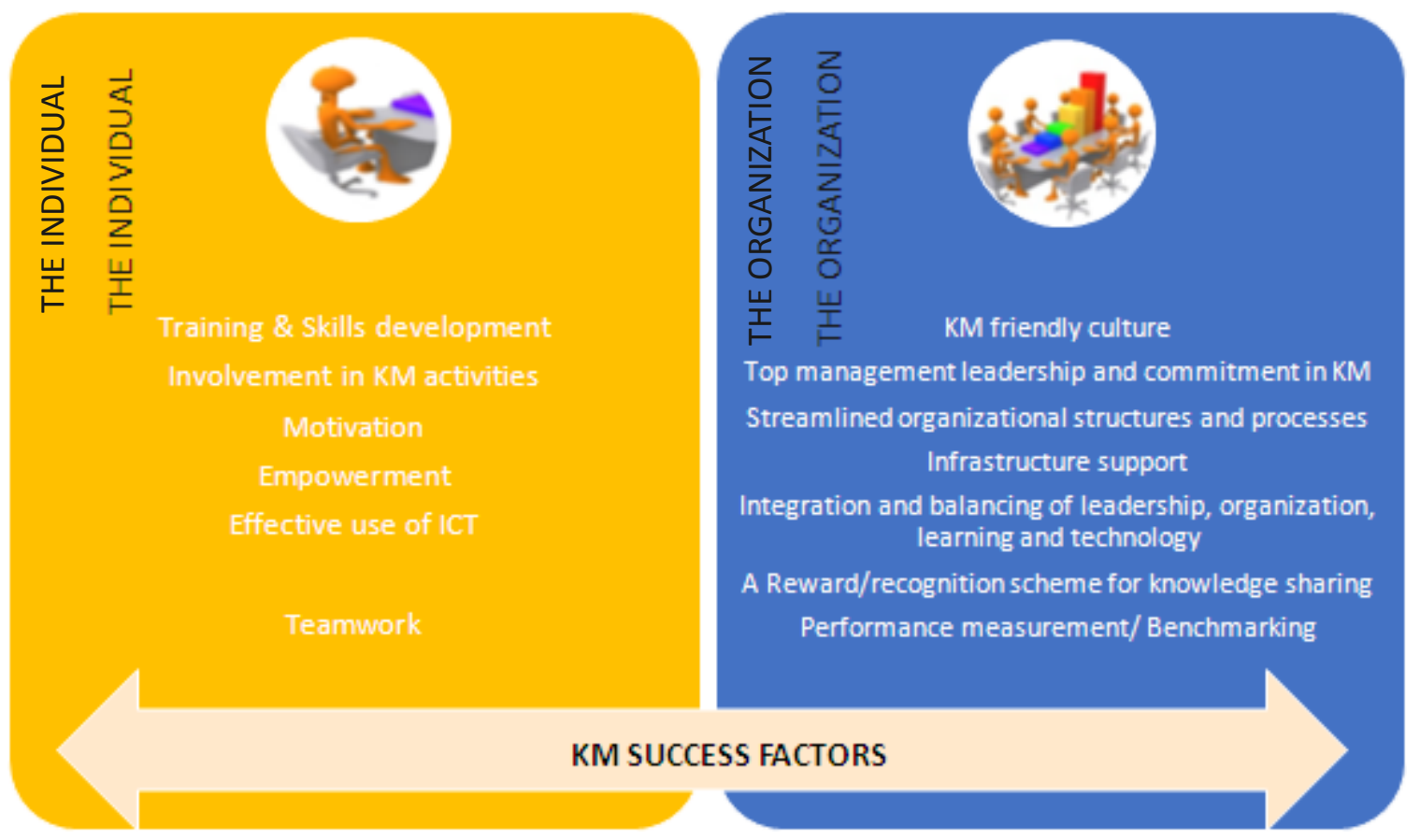

Figure 1. A Compilation of KM Success Factors

\section{The KM Culture}

Among the critical success factors for $\mathrm{KM}$ at the organizational level is the existence of a knowledge-friendly and KM-enabling culture within the organization. A KM-friendly national culture would also be preferable. The present project work focuses on culture and investigates the characteristics of what constitutes a $\mathrm{KM}$ culture.

An organization's culture is created from the fundamental assumptions and beliefs that are shared by an organization's members. It is found to operate unconsciously and it defines the organization's view of itself and its environment [9]. It involves the values, principles, unwritten rules, norms, and procedures used within the organization.

A KM-enabling culture is defined as a trusting knowledge culture that is directed towards rewarding innovation, learning, experimentation, scrutiny and reflection [10]. Trust among the organization's members is a must for sharing knowledge [4]. Within an organization, culture impacts and is impacted by infrastructure and strategy, as well as the organization's mission, vision, objectives, and goals. The national culture also affects the values and practices of every organization which is attempting a KM implementation [4].

Anthropologists agree on some basic characteristics of culture. These are: (a) culture is learned; it involves learned behaviour), (b) culture is shared between the members of a group but it is not necessarily homogenous, (c) culture is based on symbols the most important of which is language, (d) culture is integrated as it constitutes a composite of all of its parts, (e) culture is dynamic in that it interacts with other cultures and change.
Via the culture people create expectations of behaviours. These expectations can result into constructive interactions which promote knowledge sharing but also non-constructive interactions and thereby actions that hinder knowledge exchange. Constructive and defensive cultures in relation to individual and organizational outcomes that promote KM success have been studied by Balthazard and Cooke [11]. Constructive norms were found to be positively associated with both individual outcomes such as role clarity, communication quality, organizational fit, creativity, and job satisfaction, as well as organizational outcomes such as quality of products and services, quality of customer service, organizational adaptability, limited turnover, and quality of the workplace. All of these outcomes, individual and organizational, are considered to promote KM success. On the other hand, defensive cultures, both passive and aggressive, are negatively related with the above individual and organizational outcomes that may bring KM success [11]. There is also support that within an organization there may be a variety of cultures. This view may explain why some organizational units exhibit behaviours that are counter to the organization's expressed values or mission [11].

Is a competitive or a supportive culture better for the creation of a knowledge sharing atmosphere? Additional research supports that a competitive culture leads to individuals keeping their knowledge for themselves whereas a supportive culture may demote their self-interest and make them feel even morally obligated to share [12], [13], [14], [15] cited in [16].

The absence of some of the above cultural attributes or the existence of one or more of the following cultural barriers may jeopardize the perseverance of a KM culture. Cultural barriers may be raised from unclear priorities; 
distrust of data use [7]; lack of rewards/recognition for knowledge sharing; organizational inefficiencies (wrong person at wrong position); knowledge sharing not a part of daily work; privileged positions used for own personal benefit; lack of participation; lack of trust; lack of training; and unwillingness to share knowledge.

The role of management in creating a KM-enabling culture must also be emphasized. Managers and leaders should actively encourage the creation and use of knowledge. Additionally, management should promote the organization's workforce to build a positive orientation to knowledge which suggests that they become intellectually curious, they are willing and feel free to explore and they are willing to share without feeling that sharing knowledge will result in them losing power or will cost them their jobs.

Alongside to the creation of a KM-enabling culture, knowledge sharing should be further encouraged by establishing a value system which should be characterized by non-linear, dynamic and interdependent relationships. A team spirit and benefits derived by other users may also motivate users towards knowledge sharing. It is not uncommon for people to share knowledge for altruistic pro-social reasons [15] as for example in the case of Wikipedia. Motivating employees towards knowledge sharing and learning is also not uncommon. For example Ernst and Young [17] and Price Waterhouse [18] devised reward mechanisms for knowledge sharing activities whereby such activities are tied to the employee's performance evaluation.

It is also supported that only by developing the necessary organizational culture, can an organization gradually change the pattern of interaction between people, technologies, and techniques, because the core-competencies of an organization are entrenched deep into organizational practice [19]. Finally, in the case that culture needs to change to form what has been described as a KM-enabling culture, the ability or inability to change it, which may itself be affected by a number of conditions, is crucial. In such cases, the organization should not neglect the resistance from cultural inertia and the difficulty that this causes in transferring the knowledge to effectively implement better business practices [6].

\subsection{KM and the Academia}

The characteristics of a KM-enabling culture and all of the other related issues as these were already discussed are in general valid for all of the types of organizations. In the meantime some additional issues may be raised in relation to developing a knowledge sharing culture in an educational organization. Focused research carried out in the area of education reveals some of these concerns which are presented below.

Would you feel secure to share your knowledge with a colleague? Some would say "Not sure". In fact, it may be understandable to feel insecure in sharing knowledge at the work place as knowledge is regarded to be a valuable resource. Actually, it is not uncommon that individuals may not share information with their departmental peers, supervisors, or other colleagues based on the belief that this provides them with an inherent advantage in bargaining and negotiation [2]. To what extend is this premise applicable to educators who by definition must practice knowledge sharing? Albeit, knowledge sharing is the essence of education how ready are educators to share their knowledge among themselves?

Academics are judged upon their teaching duties, their research output, and their broader contribution to the university community and the society. Knowledge sharing is the heart of all three tasks although knowledge may be directed towards a different recipient every time. A study conducted by Cheng and his collaborators (Cheng, et al., 2006) to examine knowledge sharing behaviours among academics in a knowledge-based institution, being a university, focused on the factors which may affect academics' willingness to share knowledge. Organizational, individual, and technology factors were examined and the overall findings revealed that incentive systems and personal expectations are the two key factors in urging academics to engage in a knowledge sharing activity. "Forced" participation which was attempted did not work as expected and appeared to be an ineffective policy in cultivating a sharing behaviour among academics. Instead, academics responded to a performance-based incentive system and the general conclusion was that it is important to provide the "right" incentive system and understand individual's expectations towards knowledge-sharing in order to facilitate a knowledge sharing behaviour [20].

In a different study, Alotaibi and co-researchers [21] aimed to investigate the factors that affect academics' behaviour towards knowledge sharing using Web technology. The following groups of factors are identified as most important for shaping the knowledge sharing behaviour of staff: motivation factors; IT acceptance; and organizational culture. The lack of time and the high level of effort required for knowledge sharing activities back the support that motivation is the biggest issue. IT acceptance is reached as an outcome of the individual's evaluation of the usefulness and the ease of use of the particular technology. Finally, organizational culture entails trust between employees, time availability, leadership directives and practices, and the necessary IT support.

Intellectual property is another issue which tough it not explicitly addressed in the literature as either a knowledge sharing barrier or an issue which requires regulation it is interesting to consider. In fact, the Higher Education Funding Council for England (HEFCE) commissioned a study in the year 2010 on intellectual property [22]. The study showed that $19 \%$ of the academics in the top 6 high research HEIs felt that intellectual property and other issues relating to the terms of interactions of knowledge exchange nature with external organizations, could act as a barrier for their knowledge exchange interactions. In particular, these concerns were primarily raised by academics in the science, technology, engineering and mathematics disciplines.

In conclusion, in order to overcome this natural tendency 
by individuals to protect knowledge and not share, people must be convinced, rewarded or recognized properly [8]. More importantly special attention should be given to the sharing of incomplete, inaccurate or ambiguous information because of competing interests. The motivation of employees and others, e.g. other organizations, customers, suppliers, etc., to share accurate and timely information is closely paired with the mutual existence of trust which in turn depends on the prevailing sharing culture [2]. The same pertains to the sharing of knowledge.

\section{Research Methodology}

The present study was conducted as part of a broader consultation project aiming at the implementation of knowledge management in a privately owned European institution of tertiary education. Focusing on the aspects of the investigation relating to the $\mathrm{KM}$ culture within the Higher Education Institution (HEI) the authors are herewith aiming at extracting and further investigating those attributes which would synthesize a KM-enabling culture in a HEI.

The study collected qualitative data via the utilization of focus groups and in-depth interviews. Two focus groups were formulated. The first one comprised faculty members from different schools, at different ranks, and with varied experience at the current institution. The second comprised members of the staff from different functional units and with a varied service time at the institution. Individual in-depth interviews were also used to collect the opinions, views, and experiences of top executives of the institution in relation to current $\mathrm{KM}$ activities and future plans. All collected data were transcribed, compiled and analyzed using the Miles and Huberman General Analytical Technique [23].

\section{Characteristics of the KM Culture}

Although the conducted study was not dedicated at examining the HEI's culture but was more broadly investigating the current practices and future plans of the $\mathrm{HEI}$ in relation to $\mathrm{KM}$ practices, it allowed the authors to initially and broadly shape the institution's culture in the context of a KM-enabling environment. A set of attributes relating to a KM culture in the HEI were extracted. These are presented herewith along with selected related contributions made by the faculty, staff, and administrators of the HEI who participated in the study.

A KM-enabling culture is therefore characterized by (see Figure 2):

\section{- Knowledge Sharing}

- Knowledge sharing should exist at the individual, departmental and organizational level

- Possible knowledge sharing between the organization and its external stakeholders may also be developed

\section{- Appropriate Leadership}

- Leaders should actively practice and encourage KM

- Leaders should respect past records and be interested to keep them in archives

- Leaders should cultivate a shared sense of direction, excitement for learning and mutual trust

- Leaders should encourage collaborations and healthy competition but not antagonisms between individuals and/or departments

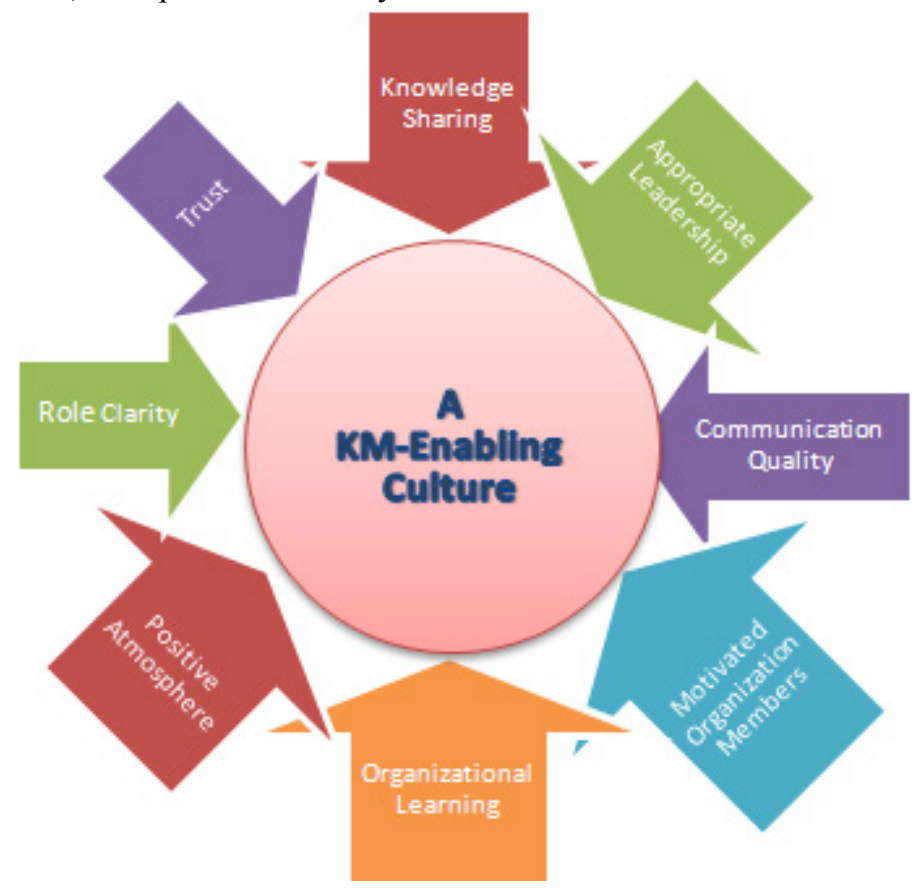

Figure 2. Attributes of a KM-Enabling Culture 
- Communication Quality

- People should interact with mutual respect and collaborate to share knowledge

- Collaborations should be developed between individuals, teams, departments and also with external partners

\section{- Motivated Organization Members}

- Includes extrinsic motivation which may be established to include appropriate rewards and/or reciprocal benefits

- May additionally include intrinsic motivation which may relate to self-efficacy, the enjoyment of assisting others and the interest to improve one's abilities, i.e., knowledge, skills, experiences, etc.

- Involves establishing the "right" incentive system

- Organizational Learning

- Should value learning from one's past

- Involves collecting best practices, reflecting on KM practices and sharing KM experiences

- Entails a continuous quest for knowledge between the organization's members

- Should offer ways to enable and enhance learning practices between the organization's members

- Positive Atmosphere

- Should empower by all possible means the organization's members to practice KM, for example via the implementation of appropriate technological models

- Organizational members should exhibit a team spirit

- Cultivate an environment which will promote professional and social interactions between its members

- Cultivate a shared sense of direction and excitement

- Role Clarity

- Prevent and resolve possible conflicts resulting from a confusion in regards to responsibilities and jurisdiction

- Trust

- Involves trust in the knowledge received to be the best in terms of currency, accuracy and completeness

- Also involves trust that knowledge sharing will be done in appropriate, ethical ways

- Expects practicing $\mathrm{KM}$ with transparency in collecting best practices, reflecting on practices and sharing experiences

- Requires the careful handling of copyrights, sensitive, and proprietary knowledge

\section{Participants' Comments}

With their participation in the undertaken study faculty, staff and administrators of the HEI have articulated their appreciation for the need for KM in saying that:

- $\quad$ There is a need to provide in a systematic way all this wealth of experience / knowledge / expertise so that someone will be able to use it if they take over a position in our units... We want to establish a system for the transfer of knowledge."

- "Knowledge sharing is part of the nature of academia and a university environment."

- "If you do not want to learn you will fail. When the organization learns it does not mean that everybody learns. Not only learning about what you are doing; it is also learning new things."

As for their concern raised by the organization members regarding the realization of a KM-enabling culture, these are better expressed through their comments some of which follow:

- "If you provide them the means and the time people are willing to learn."

- "Social interactions are very important for all organizations. It is not just the dissemination of knowledge that should interest us, but the key is how people interact and collaborate to share the knowledge, along to the existence of a positive environment."

- "People can be trained, if there is a willingness, how to speak to each other. A culture can be cultivated."

- "Why should people take an initiative if their efforts are not rewarded? Quite often it is just a question of being recognized and appreciated."

- $\quad$ It requires an individual and an organization value system to learn from past mistakes in order to go forward."

- "Should work on the emotional level on keeping people happy."

- "Maybe one of our weaknesses is sometimes a competition that may exist between departments. This may be caused by the size of the organization or the un-clear delegation of duties, overlapping of responsibilities, stress caused by increased work load..."

- "Sometimes there is confusion in regards to responsibilities and jurisdiction of departments or individuals by the management or colleagues or students."

- "A re-engineering of positions with clear job descriptions may be necessary."

- "Communication between relating departments may not be developed to the necessary degree."

- "There is good communication between relating departments."

- "Knowledge sharing is not a problem of individuals it is rather a bad characteristic of our culture. In other cultures things are different. Students sometimes are looking to receive inspiration from their lecturers. Our discussions revolve around our everyday tasks; they lack spirituality."

In some cases participants were not in full agreement between them but rather expressed contradicting viewpoints, such as: 
- "No problem with motivation and trust."

- "In general there is motivation... Every time we approach people with information there is response, there is readiness, ..."

- "Has to do with the motivation of the person. Generally speaking our society is not characterized by a strong work ethic. Most people do not want to work."

- "We need somebody to motivate the people and cultivate the culture."

\section{Other Issues Necessary for the KM Success}

Additionally employees' views on related aspects of the organization's functions revealed a number of issues which are associated with the success of a KM implementation with a HEI. These include:

Issues relating to organizational structure:

- Maintenance of an organizational structure which will be promoting knowledge sharing;

- Resolution of any conflicts such as conflicting goals and responsibilities between the organization's departments which may sometimes be influencing people's behaviours in relation to knowledge sharing.

Issues relating to networking and communication:

- The creation of the necessary networks for knowledge transfer and sharing;

- Networking abilities through established avenues of communication with colleagues, experts and other benefactors, such as students, and others;

- Dissemination of knowledge between those who need it in a variety of ways in order to ensure easier and enhanced access (supporting the KM function of delivering the right knowledge to the right people at the right time);

- The promotion of internal cooperation among organization members;

- The promotion of external cooperation with industry consortia and other institutes.

Issues relating to technology and related skills:

- Ultimate use of available ICT to connect with others;

- Organizational investments in new ICT to enhance collaboration, communication, sharing, etc.;

- Ways of dealing with the technology fear and the expected resistance to change.

Issues relating to organizational processes:

- Updated knowledge of different areas of expertise and interests;

- A clear allocation of responsibilities for KM functions to individuals and offices;

- Carefully designed KM activities which must follow the organizational processes' natural work flow and must be embedded in organizational activities so as to require minimum additional effort.
Issues relating to management involvement:

- A management team actively and openly supporting KM;

- Conceptualization and formalization of KM activities by means of adopting a clear KM strategy.

Issues relating to KM on-going activities:

- Constant identification of knowledge gaps in the organization and filling them by recruiting new organizational members and/or providing such knowledge to the organization members along with the means necessary to attain it;

- Acknowledgement and follow up of the evolution of the organization by designing new KM activities and re-designing/re-engineering the existing KM activities as deemed necessary;

- The regular measurement of KM practices and the close following of any progress made.

\section{Conclusions and Plans for Future Research}

A KM-enabling culture is overall a trusting, supportive, non-individualistic culture which promotes sharing for the common goal of organizational prosperity. Initial and on-going efforts will be required at all levels of the organization in order to create and maintain such a culture. Bottom-up initiatives as these are taken at the employee level should be welcomed and may cause change in the management of the organization. At the same time top-down initiatives involving new directions and changes introduced by the management to shape up new behaviours and actions between the organization's employees are desirable. The realization and maintenance of such a culture should be seen as a challenging task. Finally, the attainment of a KM-enabling culture will most definitely be rewarding for the organization which will subsequently have the ability to employ knowledge management and expect to enjoy its benefits.

The present study was qualitative and involved the employee force, both staff and faculty, of a European HEI. A part of the study aimed at understanding a KM-enabling culture and the aspects of the overall organizational culture which relate to knowledge sharing. This let to shaping a KM-enabling culture within a HEI and identifying its main characteristics. Alongside to the examination of the knowledge sharing culture and by considering the feedback received from the organizational force it was possible to identify a number of related issues and concerns which are also necessary for the implementation of KM within an organization.

It is in our future plans to investigate further the KM-enabling culture by approaching more HEIs in order to reach more conclusive results which may be generalizable in the sector of higher education. 


\section{REFERENCES}

[1] C. W. Holsapple and K. D. Joshi, "A Knowledge Management Ontology," in Handbook on Knowledge Management 1, C. W. Holsapple, Ed., Berlin, Springer, 2004, pp. 89-124.

[2] Y. Malhotra, "Why Knowledge Management Systems Fail: Enablers and Constraints of Knowledge Management in Human Enterprises," in Handbook of Knowledge Management 1, C. W. Holsapple, Ed., Berlin, Springer, 2004, pp. 577-599.

[3] S. Chong and Y. Choi, "Critical Factos in the Successful Implementation of Knowledge Management," Journal of Knowledge Management Practice, vol. , no. June, p. , 2005.

[4] M. Stankosky, "Advances in Knowledge Management: University Research Toward an Academic Discipline," in Creating the Discipline of Knowledge Management, M. (. Stankosky, Ed., Washington, Elsevier

Butterworth-Heinemann, 2005, p.

[5] D. Bennet and A. Bennet, "The Rise of the Knowledge Organization," in Handbook of Knowledge Management Vol.1, , Springer, 2003, pp. 5-20.

[6] J. Brown, "Conversation," Knowledge Directions: The Journal of the Institute for Knowledge Management, vol. 1, no. , p. , 1999.

[7] L. Petrides and T. Nodine, "Knowledge Management in Education: Defining the Landscape," 2003. [Online]. Available: www.iskme.org. [Accessed 17 February 2014].

[8] A. Chua, "Knowledge Sharing: A Game People Play," Aslib Proceedings, vol. 55, no. 3, pp. 117-129, 2003.

[9] E. Schein, Organizational Culture and Leadership, Washington: Jossey-Bass Publishers, 1985.

[10] V. Allee, "Twelve Principles of Knowledge Management," Training and Development, vol. 51, no. 11, pp. 71-74, 1997.

[11] P. Balthazard and R. Cooke, "Organizational Culture and Knowledge Management Success: Assessing the Behavior-Performance Continuum," in Proceedings of the 37th Hawaii International Conference on System Sciences, , 2004.

[12] U. Kulkarni, S. Ravindran and R. Freeze, "A Knowledge Management Success Model: Theoretical Development and Empirical Validation," Journal of Management Information Systems, vol. 23, no. 3, pp. 309-347, 2006.
[13] M. van Alstyne, "Create Colleagues, Not Competitors," Harvard Business Review, vol. 83, no. 9, pp. 24-28, 2005.

[14] S. Voelpel, M. Dous and T. Davenport, "Five Steps to Creating a Global Knowledge-Sharing System: Siemens' ShareNet," Academy of Management Executive, vol. 19, no. 2, pp. 9-23, 2005.

[15] M. Wasko and S. Faraj, "It is What One Does: Why People Participate and Help Others in Electronic Communities of Practice," The Journal of Strategic Information Systems, vol. 9, no. 2-3, pp. 155-173, 2000.

[16] C. Loebbecke and K. Crowston, "Knowledge Portals: Components, Functionalities, and Deployment Challenges," in Conference Proceedings ICIS 2012, , 2012.

[17] Ernst \& Young, "EY Celebrates 15 Years as a Global Knowledge Leader," 2013. [Online]. Available: http://www.ey.com/GL/en/Newsroom/News-releases/News EY-celebrates-15-years-as-a-global-knowledge-leader. [Accessed 10 December 2014].

[18] C. O'Dell and C. Grayson, "If Only we Knew What we Know: Identification and Transfer of Internal Best Practice," California Management Review, vol. 40, no. 3, pp. 154-174, 1998.

[19] B. Ganesh, "Knowledge Management in Organizations: Examining the Interaction between Technologies, Techniques, and People," Journal of Knowledge Management, vol. 5, no. 1, pp. 68-75, 2001.

[20] M. Cheng, J. S. Y. Ho and P. Lau, "Knowledge Sharing in Academic Institutions: a Study of Multimedia University Malaysia," Electronic Journal of Knowledge Management, vol. 7, no. 3, pp. 313-324, 2006.

[21] H. Alotaibi, R. Crowder and G. Wills, "Investigating Factors for E-Knowledge Sharing amongst Academic Staff," in eKNOW 2014 : The Sixth International Conference on Information, Process, and Knowledge Management, , 2014.

[22] PACEC and the Centre for Business Research at the University of Cambridge, "The Intellectual Property Regime and its Implications for Knowledge Exchange," 2010. [Online]. Available: http://www.pacec.co.uk/publications/The Intellectual Prope rty_Regime_and_its_Implications_for_Kñowledge_Exchang e.pdf. [Accessed 10 December 2014].

[23] M. Miles and A. Huberman, Qualitative Data Analysis: A Sourcebook of New Methods, ed., Thousand Oaks: Sage, 1994. 